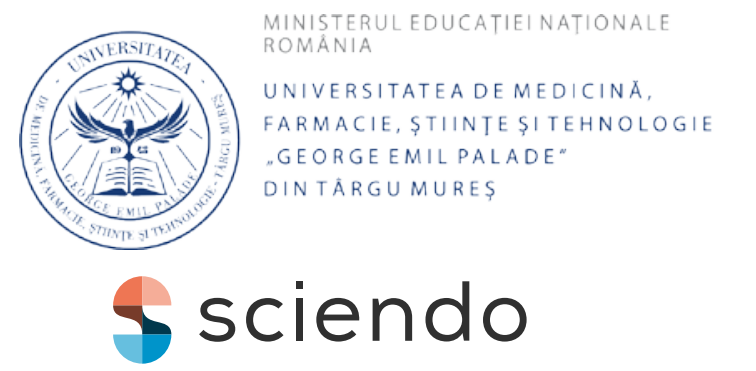

\author{
Acta Marisiensis. Seria Technologica \\ Vol. 18 (XXXIV) no. 2, 2020 \\ ISSN 2668-4217, ISSN-L 2668-4217
}

10.2478/amset-2020-0013

\title{
BUCKLING ANALYSIS OF INNOVATIVE CORRUGATED COLUMN BY USING RESPONSE SURFACE METHODOLOGY
}

\author{
Mohd Reyaz Ur RAHIM" ${ }^{1, ~ *, ~ P r e m ~ K u m a r ~ B H A R T I ~}{ }^{2}$ \\ ${ }^{I}$ Department of Mechanical Engineering, Integral university, Lucknow, Uttar Pradesh, India \\ ${ }^{I}$ rrahim@iul.ac.in \\ ${ }^{2}$ Department of Mechanical Engineering, Integral university, Lucknow, Uttar Pradesh, India \\ ${ }^{2}$ bharti.pk@iul.ac.in
}

\begin{abstract}
Tubular steel structures with slender compression cross-sections are prone to local buckling. In this paper the axial compression is investigation of the innovative fabricated structural steel column consisting of sinusoidal corrugated pattern. When it comes to the design of compressive individuals, buckling is a crucial layout provision. The paper describes the effect of variation in the sectional properties like mean diameter, thickness, amplitude, and frequency of corrugation on the buckling axial load. A quadratic model was developed to correlate the independent variables for maximum buckling load by using central composite design (CCD) method. Subsequently ANOVA, a statistical tool is used to analyse and compare the different combinations and finding the most influential factor on buckling load. Response surface methodology is adopted to review the interaction models between the different combinations.
\end{abstract}

Key words: Innovative hollow column, Linear buckling analysis, ANSYS, Design of experiment, Response surface method

\section{Introduction}

(Innovative) In 1990's, Migita et al. [1] conducts 23 axial compressive tests on closed polygonal section steel columns. Some samples were stub columns with rectangular, pentagonal, hexagonal, heptagonal, and octagonal sections, whilst the others were medium-length columns with rectangular, hexagonal, and octagonal sections. Their research resulted in an empirical formula based on the compression tests to predict local buckling strength and interaction of closed polygonal steel columns between the local and total buckling capacities. An innovative $\mathrm{X}$ section was suggested by Chen and Jin [2] with intermediate stiffeners to improve the local buckling stress of thin-walled samples. The proposed stub column was tested as hollow steel tubing as well as concrete-filled steel tubing.

From a material perspective, many construction materials, such as steel, aluminum, and the like, fall into the category of isotropic material. Moreover, such materials exhibit direction-dependent properties; thus, such materials are called anisotropic. The lateral deformations in other main directions may be smaller or greater in anisotropic materials stressed in one of the main directions than the deformation in the direction of the stress applied depending on the material properties [3]. The matrix of the material constants for a general anisotropic material includes 21 independent constants. It means all strains are linked to all stresses. This section involves some materials such as wood, plywood, and fibre-

(C) 2020 Published by University Press. This is an open access article under the CC BY-NC-ND license (http://creativecommons.org/licenses/CC-BY-4.0/) 
reinforced plastics etc. These materials exhibit normal anisotropy. Besides plates made from anisotropic materials, due to their structure such as corrugated and stiffened plates, a number of plates also made of isotropic materials may also fall into the category of anisotropic plates. Such anisotropy form is called structural anisotropy [3].

Aoki and Ji [4] developed an innovative way of increasing the capacity of steel columns without sacrificing other properties. The aim was to weld steel tubes to square and triangular steel column apexes. It was concluded that the plates provide lateral restraint to the steel tubes that postpone the buckling while the total load supported by the manufactured sections exceeded the load resulting from the summation of the capacity of the individual components.

Nassirnia et al. uses UHS (ultra-high strength steel) tubes that are welded to hollow corrugated column apexes [5]. The performance of these sections is investigated under compression, both experimentally and numerically. Specific trapezoidal corrugation profiles are used to determine the impact of corrugation parameters on the columns proposed. Last, accost analysis is conducted to demonstrate the superior performance of innovative columns by comparing the fabrication cost of proposed sections with conventional sections fabricated from flat plates. Xiaolin et al. developed a theoretical solution for the mean crushing force of the star-shaped tubes were derived, and the theoretical solutions show an excellent agreement with the experimental results [6].

This paper investigates the combined effect of mean diameter, amplitude, frequency and thickness on buckling load, and the process parameters were analysed using central composite design (CCD) in conjunction with RSM method.

\section{Proposed corrugated column}

Fig. 1 shows the hollow corrugated column with sinusoidal pattern used in the present paper. Since it is found that corrugation makes the structure more strength along the length of the column [7] as compared to conventional circular hollow columns. As buckling is the most important phenomenon as a result of axial-compression forces. Buckling analysis is used to determine buckling loads; the critical loads at which a structure becomes unstable, and the different ways that the structural member can deform which known as buckling mode shapes. In the present work, the corrugation parametric is analyzed with the range and set of combinations as shown in Table 2 and Table 3 by using design of experiment, in which Table 2 gives the details of all parameters in their coded and actual form and based on which the total number of simulation need to be performed is shown well in Table 3 with complete details keeping the length constant as $3048 \mathrm{~mm}$.

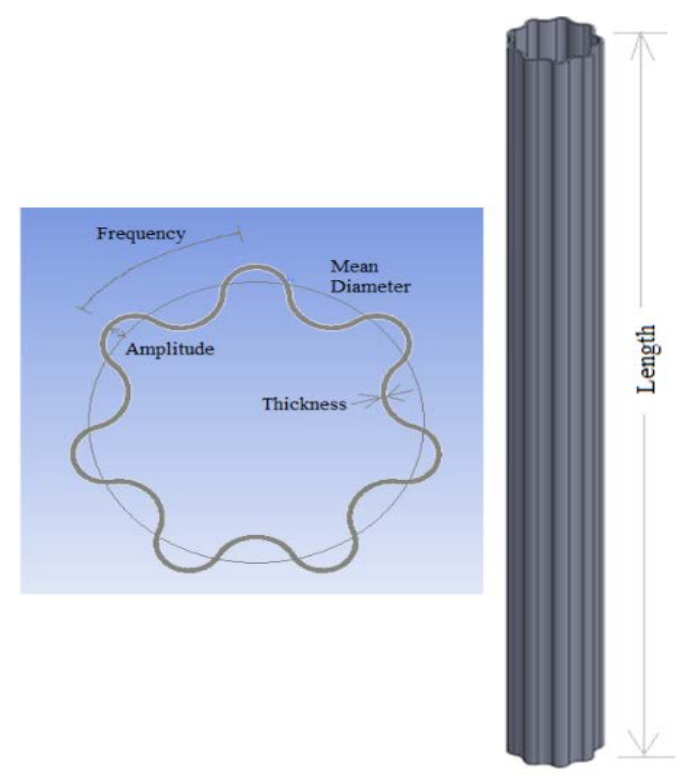

Fig. 1: A typical corrugated column 
Material used is structural steel with specifications

-Young's Modulus E=200GPa

- Poison's ratio $v=0.3$

- Density $\rho=7800 \mathrm{~kg} / \mathrm{m}^{3}$.

\section{Multivariate design of experiment}

The parameter used for buckling load by geometric parameters was analyzed by standard response surface methodology (RSM) design called central composite design (CCD). RSM is used for fitting a quadratic surface and also helps to optimize the process parameters with a minimum number of experiments and to evaluate the interaction between the parameters. [8]. RSM is a set of mathematical and statistical techniques that are useful in developing the empirical model construction, improving and optimizing process parameters and can also be used to evaluate the relationship between several factors that affect them [9]. RSM is a statistical approach that uses the quantitative data of the associated experiment to classify the regression model and optimize a response (output variable) affected by many independent variables. CCD is typically a $2 n$ factorial run with $2 n$ axial runs, and the experimental error is calculated by center runs $\left(\mathrm{n}_{\mathrm{c}}\right)$. This experimental design consists of a factorial $2 \mathrm{n}$ with \pm 1 notation coding increased by $2 \mathrm{n}$ axial points $( \pm \mathrm{a}, 0,0, .0),\left(0, \pm \mathrm{a}, 0 .(0,0, \pm \mathrm{a} \ldots 0)\right.$ and $\mathrm{n}_{\mathrm{c}}$ center points $(0,0,0 \ldots 0)$ [10]. Each variable is investigated at two levels while as the number of variables $(n)$ increases, the number of runs for a complete replication of the design is rapidly increasing. CCD was used for quadratic effect since $2 n$ factorial designs cannot be calculated separately for single second order effect. Hence, CCD has been used to establish the model for buckling load. The response with corresponding parameters was modelled in the statistical analysis to optimize the process conditions for the desired answer. ANOVA is used with the help of response surface methods to measure the statistical parameters.

In the assumed that the independent variable in the experiments are continuous, and experiments with negligible errors are controlled. The experimental design was aimed at maximizing the response variables (Y). An appropriate approximation to the true correlation between independent variables and response surfaces required to be found [10]. To reduce the error and effect of the uncontrolled factors, the experimental run was randomized. Using a second-degree polynomial equation Eq (1), the response was used to generate an empirical model correlating to the experimental variables.

$$
Y=\beta_{0}+\sum_{i=1}^{n} \beta_{i} X_{i}+\sum_{i=1}^{n} \beta_{i i} X_{i}^{2}+\sum_{i=1}^{n} \sum_{j=i+1}^{n} \beta_{i j} X_{i} X_{j}+\varepsilon
$$

where $\mathrm{Y}$ is the expected response; $\beta_{0}$ the constant coefficient; $\beta_{\mathrm{i}}$ the linear coefficients; $\beta_{\mathrm{ii}}$ the quadratic coefficients; $\beta_{\mathrm{ij}}$ the interaction coefficients; $n$ the number of factors observed and optimized in the experiments; $\mathrm{X}_{\mathrm{i}}$ and $\mathrm{X}_{\mathrm{j}}$ the coded values of the variable leaching process parameters; and $\varepsilon$ the random error. The codes are calculated as a function of the range of each factor as shown in Table 1 [11]. The test variables were coded in developing of the regression equation according to Eq. (2).

$$
\chi_{i}=\frac{X-X_{i}^{*}}{\Delta X_{i}}
$$

Table 1: Relationship between the coded and actual of the variables

\begin{tabular}{c|c}
\hline Code & The actual level of variable \\
\hline$-\alpha$ & $\mathrm{X}_{\min }$ \\
\hline-1 & {$\left[\left(\mathrm{X}_{\max }+\mathrm{X}_{\min }\right) / 2\right]-\left[\left(\mathrm{X}_{\max }-\mathrm{X}_{\min }\right) / 2 \beta\right]$} \\
\hline 0 & $\left(\mathrm{X}_{\max }+\mathrm{X}_{\min }\right) / 2$ \\
\hline+1 & {$\left[\left(\mathrm{X}_{\max }+\mathrm{X}_{\min }\right) / 2\right]+\left[\left(\mathrm{X}_{\max }-\mathrm{X}_{\min }\right) / 2 \beta\right]$} \\
\hline$+\alpha$ & $\mathrm{X}_{\max }$ \\
\hline
\end{tabular}

Note: $\beta$ is $2^{\mathrm{n} / 4} ; \mathrm{n}$ is the number of variables (mean diameter, amplitude, frequency and thickness) and $\mathrm{n}=4$ 
Table 2: Independent variables and their coded levels for the central composite design

\begin{tabular}{|c|c|c|c|c|c|c|}
\hline \multirow{2}{*}{$\begin{array}{c}\text { Independent } \\
\text { variable }\end{array}$} & \multirow{2}{*}{ Symbol } & $-\alpha$ & Low & Medium & High & $+\alpha$ \\
\cline { 3 - 7 } & & -2 & -1 & 0 & 1 & 2 \\
\cline { 3 - 7 } Mean Diameter & $\mathrm{X}_{1}$ & 228.6 & 247.65 & 266.7 & 285.75 & 304.8 \\
\hline Amplitude & $\mathrm{X}_{2}$ & 4.8 & 6.1 & 7.4 & 8.7 & 10 \\
\hline Thickness & $\mathrm{X}_{3}$ & 0.25 & 5.0625 & 9.875 & 14.68 & 19.5 \\
\hline Frequency & $\mathrm{X}_{4}$ & 5 & 7 & 9 & 11 & 13 \\
\hline
\end{tabular}

Table 3: Experimental factors in coded and actual units and experimental responses

\begin{tabular}{|c|c|c|c|c|c|c|c|c|c|}
\hline \multirow{2}{*}{ 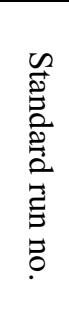 } & \multicolumn{4}{|c|}{$\begin{array}{l}\text { Independent variable in } \\
\text { coded } \\
\text { form }\end{array}$} & \multicolumn{4}{|c|}{ Independent variable in actual form } & \multirow{2}{*}{ 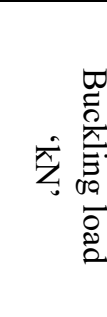 } \\
\hline & $\underline{x}$ & 爻 & $\underset{\omega}{x}$ & $\underset{+}{\not}$ & 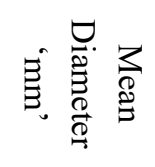 & 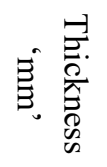 & 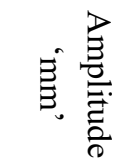 & 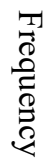 & \\
\hline 1. & 1 & 1 & -1 & -1 & 285.75 & 8.7 & 5.0625 & 7 & 3892 \\
\hline 2. & -1 & 1 & -1 & 1 & 247.65 & 8.7 & 5.0625 & 11 & 2593 \\
\hline 3. & -1 & -1 & -1 & 1 & 247.65 & 6.1 & 5.0625 & 11 & 1875 \\
\hline 4. & 1 & -1 & 1 & 1 & 285.75 & 6.1 & 14.6875 & 11 & 3561 \\
\hline 5. & 0 & 0 & 0 & 0 & 266.7 & 7.4 & 9.875 & 9 & 2975 \\
\hline 6. & 1 & -1 & -1 & -1 & 285.75 & 6.1 & 5.0625 & 7 & 2796 \\
\hline 7. & 0 & 0 & 0 & 0 & 266.7 & 7.4 & 9.875 & 9 & 2975 \\
\hline 8. & 1 & -1 & 1 & -1 & 285.75 & 6.1 & 14.6875 & 7 & 3102 \\
\hline 9. & -1 & 1 & -1 & -1 & 247.65 & 8.7 & 5.0625 & 7 & 2520 \\
\hline 10. & 1 & 1 & -1 & 1 & 285.75 & 8.7 & 5.0625 & 11 & 3977 \\
\hline 11. & 1 & 1 & 1 & -1 & 285.75 & 8.7 & 14.6875 & 7 & 4339 \\
\hline 12. & 1 & -1 & -1 & 1 & 285.75 & 6.1 & 5.0625 & 11 & 2861 \\
\hline 13. & -1 & -1 & 1 & -1 & 247.65 & 6.1 & 14.6875 & 7 & 2101 \\
\hline 14. & -1 & -1 & -1 & -1 & 247.65 & 6.1 & 5.0625 & 7 & 1821 \\
\hline 15. & 0 & 0 & 0 & 0 & 266.7 & 7.4 & 9.875 & 9 & 2975 \\
\hline 16. & 0 & 0 & 0 & 0 & 266.7 & 7.4 & 9.875 & 9 & 2975 \\
\hline 17. & -1 & -1 & 1 & 1 & 247.65 & 6.1 & 14.6875 & 11 & 2491 \\
\hline 18. & -1 & 1 & 1 & 1 & 247.65 & 8.7 & 14.6875 & 11 & 3456 \\
\hline 19. & 1 & 1 & 1 & 1 & 285.75 & 8.7 & 14.6875 & 11 & 4984 \\
\hline 20. & -1 & 1 & 1 & -1 & 247.65 & 8.7 & 14.6875 & 7 & 2914 \\
\hline 21. & 0 & 0 & 0 & -2 & 266.7 & 7.4 & 9.875 & 5 & 2768 \\
\hline 22. & 0 & 0 & 0 & 2 & 266.7 & 7.4 & 9.875 & 13 & 3276 \\
\hline 23. & 2 & 0 & 0 & 0 & 304.8 & 7.4 & 9.875 & 9 & 4350 \\
\hline 24. & 0 & 0 & 0 & 0 & 266.7 & 7.4 & 9.875 & 9 & 2975 \\
\hline 25. & 0 & 0 & 0 & 0 & 266.7 & 7.4 & 9.875 & 9 & 2975 \\
\hline 26. & 0 & 2 & 0 & 0 & 266.7 & 10 & 9.875 & 9 & 3910 \\
\hline 27. & -2 & 0 & 0 & 0 & 228.6 & 7.4 & 9.875 & 9 & 1917 \\
\hline 28. & 0 & -2 & 0 & 0 & 266.7 & 4.8 & 9.875 & 9 & 1975 \\
\hline 29. & 0 & 0 & -2 & 0 & 266.7 & 7.4 & 0.25 & 9 & 2673 \\
\hline 30. & 0 & 0 & 2 & 0 & 266.7 & 7.4 & 19.5 & 9 & 3759 \\
\hline
\end{tabular}


where $\chi_{i}$ is the $i^{\text {th }}$ independent variable of the dimensionless coded value; the uncoded value of the $i^{\text {th }}$ independent variable is denoted by $X_{i}$; similarly, at the center point, the uncoded value of the $i^{\text {th }}$ independent variable denoted by $X_{i}$; and the step change value has been defined by $\mathrm{DX}_{\mathrm{i}}[12]$.

$\mathrm{N}$ as a total number of runs or experiments means the number of tests required for the CCD, the usual $2 \mathrm{n}$ factorial points with their root in the middle. The quadratic terms generate from the center at a distance a (a value was set at 2 in this study), from a set $2 \mathrm{n}$ axial points, and run the replicates at the center to prevent error; where $n$ is the number of independent variables; The axial points $(2 n)$ are for screening analysis and readability, which tests the variance of model estimation and is constant from the design core at all points equidistant and $n_{c}$ is the number of central points that reproduce the test at the core and is very important for the independent evaluation of the experimental error. [13].

Cube points: $\quad 16$

Center points in cube: 4

Axial points: $\quad 8$

Center points in axial: $\quad 2$

$$
\mathrm{N}=2 \mathrm{n}+2 \mathrm{n}+\mathrm{n}_{\mathrm{c}}
$$

In the CCD design, eight factorial points, six axial points, and six replicates were used at the central points in four variables in the experiments. The total number of tests $(\mathrm{N})$ needed for the four independent variables thus amounts to 30 as shown in Eq. (3). Upon description of the desired range value of the variables, they are coded to \pm 1 for factor points, 0 for center points and $\pm \alpha$ for factor for the axial points.

\section{Numerical Modelling}

The linear buckling behavior was analyzed using ANSYS workbench software 18.1. The tubes are meshed with the element size of $2 \mathrm{~mm}$ and condition of constraints are: one end is fixed while load is applied on the free end.

In ANSYS, buckling analysis might be conducted using Eigenvalue buckling analysis [14]. Eigenvalue buckling analysis reveals the buckling load factor that has to be multiplied by the applied loads to reach buckling point [15]. Eigenvalue buckling analysis may be based on linear or nonlinear static analysis. Linear eigenvalue buckling analysis deals with ideal elastic structure and provides a non-conservative estimation that is useful for later complicated nonlinear buckling analyses. ANSYS provides a ready-to-use tool for eigenvalue buckling analysis and calculates buckling load factors along with buckling mode shapes.

\section{Model fitting and statistical analysis}

ANOVA (Analysis of variance) has been used for graphical analysis of the data to define the interaction between the process variables and the responses to estimate the statistical parameters.

The statistical tool Design Expert, Stat-Ease, Inc., Minneapolis, USA, was used to analyze experimental data for regression, plot the response surfaces, and plot contour at optimized level. The statistical significance within the same system was tested by the F-test. The exactness of the equipped polynomial model has been calculated by the $\mathrm{R}_{2}$ coefficient. The important model terms were evaluated by the probability value (P-value) at $95 \%$ confidence interval.

\section{Results and discussion}

\subsection{Development of model}

The statistical "Design-Expert Version 12" software has been used to study the regression analysis of result data and to get the response surface plot. The statistical parameters were examined by using ANOVA. For the buckling load study, the required geometric parameters range and coded level of variables are given in Table 3 and 4, which shows the design of experiments together with the simulation results. As the output proposed by the Design-Expert software, the quadratic model is suggested. The final empirical model in terms of a coded factor for buckling load is shown in Eq. (4):

Buckling load $(\mathrm{kN})=2974.80+1217.20 \mathrm{X}_{1}+994.65$ $\mathrm{X}_{3}+565.47 \mathrm{X}_{2}+277.47 \mathrm{X}_{4}+419.55 \mathrm{X}_{1} \mathrm{X}_{3}+77.00 \mathrm{X}_{1}$ $\mathrm{X}_{2}+48.80 \mathrm{X}_{1} \mathrm{X}_{4}+202.25 \mathrm{X}_{3} \mathrm{X}_{2}+94.25 \mathrm{X}_{3} \mathrm{X}_{4}+439.00$ $\mathrm{X}_{2} \mathrm{X}_{4}+159.68 \mathrm{X}_{1}^{2}-31.22 \mathrm{X}_{3}^{2}+242.38 \mathrm{X}_{2}^{2}+48.18 \mathrm{X}_{4}^{2}$

where the negative sign indicates the antagonistic effects, whereas the positive sign indicates the synergistic effects.

So as to fit a good model for significance of the regression model and individual model coefficients with lack of fit test was performed. The significant factors were typically rated with a confidence level of $95 \%$ based on the F-value or Pvalue (probability value). Table 4 shows the ANOVA for the data generated by Eq. (4) for buckling load. The larger value of $\mathrm{F}$ and the smaller value of $\mathrm{P}$ (Prob. $>$ F) shows more significant of the corresponding coefficient [16]. The F-value of 1462.72 indicates that the model is significant. Moreover, the model terms are significant only when the values of "Prob. > F" are less than 0.05 . 
Table 4: Analysis of variance (ANOVA) for response surface quadratic model for buckling load

\begin{tabular}{|c|c|c|c|c|c|c|}
\hline Source & Sum of Squares & df & Mean Square & F-value & p-value & \\
\hline Model & $1.777 \mathrm{E}+07$ & 14 & $1.269 \mathrm{E}+06$ & 1462.72 & $<0.0001$ & significant \\
\hline $\mathrm{X}_{1}$-Mean Diameter & $8.889 \mathrm{E}+06$ & 1 & $8.889 \mathrm{E}+06$ & 10242.64 & $<0.0001$ & significant \\
\hline $\mathrm{X}_{2}$-Amplitude & $1.919 \mathrm{E}+06$ & 1 & $1.919 \mathrm{E}+06$ & 2210.56 & $<0.0001$ & significant \\
\hline $\mathrm{X}_{3}$-Thickness & $5.936 \mathrm{E}+06$ & 1 & $5.936 \mathrm{E}+06$ & 6839.57 & $<0.0001$ & significant \\
\hline $\mathrm{X}_{4}$-Frequency & $4.619 \mathrm{E}+05$ & 1 & $4.619 \mathrm{E}+05$ & 532.24 & $<0.0001$ & significant \\
\hline $\mathrm{X}_{1} \mathrm{X}_{3}$ & $1.760 \mathrm{E}+05$ & 1 & $1.760 \mathrm{E}+05$ & 202.82 & $<0.0001$ & significant \\
\hline $\mathrm{X}_{1} \mathrm{X}_{2}$ & 5929.00 & 1 & 5929.00 & 6.83 & 0.0196 & \\
\hline $\mathrm{X}_{1} \mathrm{X}_{4}$ & 2381.44 & 1 & 2381.44 & 2.74 & 0.1184 & \\
\hline $\mathrm{X}_{3} \mathrm{X}_{2}$ & 40905.06 & 1 & 40905.06 & 47.13 & $<0.0001$ & significant \\
\hline $\mathrm{X}_{3} \mathrm{X}_{4}$ & 8883.06 & 1 & 8883.06 & 10.24 & 0.0060 & \\
\hline $\mathrm{X}_{2} \mathrm{X}_{4}$ & $1.927 \mathrm{E}+05$ & 1 & $1.927 \mathrm{E}+05$ & 222.06 & $<0.0001$ & significant \\
\hline $\mathrm{X}_{1}^{2}$ & 43712.17 & 1 & 43712.17 & 50.37 & $<0.0001$ & significant \\
\hline $\mathrm{X}_{3}^{2}$ & 1670.54 & 1 & 1670.54 & 1.92 & 0.1856 & \\
\hline $\mathrm{X}_{2}^{2}$ & $1.007 \mathrm{E}+05$ & 1 & $1.007 \mathrm{E}+05$ & 116.04 & $<0.0001$ & significant \\
\hline $\mathrm{X}_{4}^{2}$ & 3979.94 & 1 & 3979.94 & 4.59 & 0.0491 & \\
\hline Residual & 13018.31 & 15 & 867.89 & & & \\
\hline Lack of Fit & 13018.31 & 10 & 1301.83 & & & \\
\hline Pure Error & 0.0000 & 5 & 0.0000 & & & \\
\hline Cor Total & $1.779 \mathrm{E}+07$ & 29 & & & & \\
\hline
\end{tabular}

Level of every factor was determined dependent on primer expulsion. The distance of the axial points from the center was \pm 2 and it was calculated from $\mathrm{a}=(2 \mathrm{n})^{0.25}$ where $\mathrm{n}$ is the number of variables. The signal-to - noise ratio is determined by accuracy, consisting of the expected value at the design points and the average predictive error. In the present study, adequacy precision ratio is 147.2947 and is desirable due to this ratio has been greater than 4. Hence, the developed model can be used to guide the design space. The adequacy of the developed model was the main part to check the data analysis of the experiment. The normal probability and studentized residual plot were shown in Fig. 2 and it has been found that there was neither response transformation nor any apparent problem with normality. This signifies that for all values of the response, the random scatter plot, the variance of original observation is constant, and this was an indication that there was no need for transformation of response variables. 


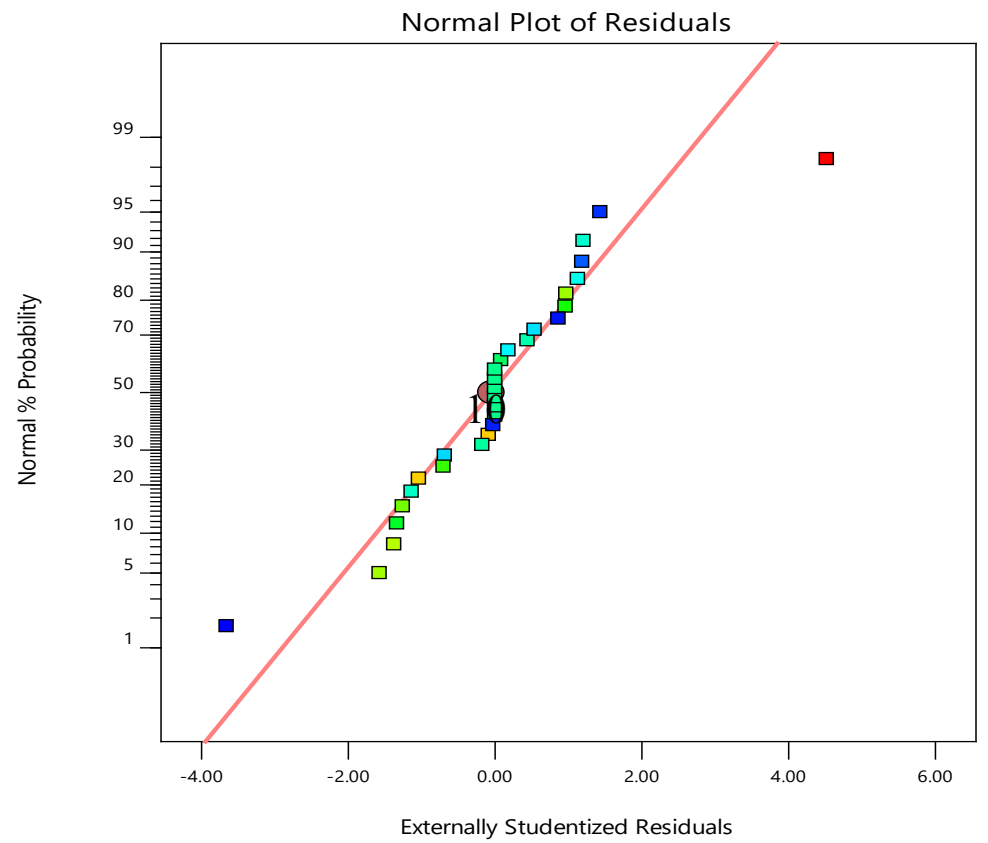

Fig. 2: External studentized residuals and normal percentage probability plot for buckling load

Actual and the predicted percentage for buckling load was shown in Fig. 3.

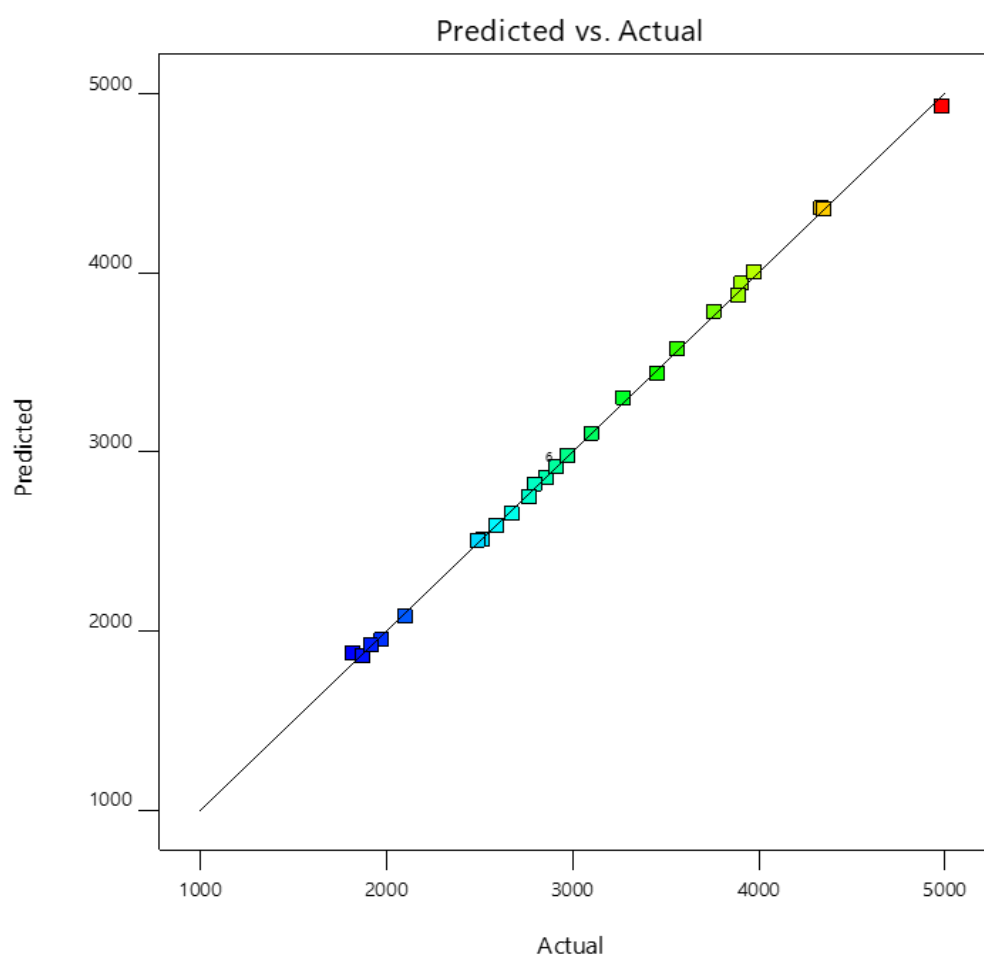

Fig. 3: Actual and predicted plot of buckling load $(\mathrm{kN})$

It was found that the values of $R_{2}$ and adjusted $R_{2}$ (Radj) were $99 \%$ and $99 \%$ respectively. The value of $\mathrm{R}_{2}$ describes up to what extent perfectly model can estimate the numerical data points and the adjusted $\mathrm{R}_{2}$ measured the amount of variation about mean explained by the model. The predicted $\mathrm{R}_{2}$ value was 0.9958 , which was near close to $R_{2}$ value. It was revealed that the numerical data for buckling 
load is fitted well with the predicted value of the model. The standard deviation for the model was 29.46. The smaller value of standard deviation shows good model that gives near value between predicted and actual values for the responses. The statistical parameter obtained from ANOVA was shown in Table 5.

Table 5: Statistical parameters obtained from the analysis of variance (ANOVA) for the models for buckling load

\begin{tabular}{cc}
\hline Insignificant factors excluded & Buckling load 'kN' \\
\hline Standard deviation (S.D.) & 29.46 \\
Mean & 3058.61 \\
Coefficient of variance (C.V) \% & 0.9632 \\
Adeq. precision & 147.2947 \\
$\mathrm{R}_{2}$ & 0.9993 \\
Adjusted $\mathrm{R}_{2}$ & 0.9986 \\
Predicted $\mathrm{R}_{2}$ & 0.9958 \\
\hline
\end{tabular}

\subsection{Combined effect of sectional parameters on buckling load}

Response surface methodology was used to investigate the individual and interaction effect of the four-factor on buckling load. Based on ANOVA, the results were obtained, the effects of geometric factors on buckling load, corresponding threedimensional response surface plots were shown in Fig. 4-9 and the response model was represented in Eq. (4). Fig. 3 show the relationship between the actual and predicted values of buckling load. The mean diameter, thickness, amplitude and frequency have significant effects on the buckling load. With the response surface analysis method, it was fund rom Table 3 that geometric factors influence the buckling load. It has been found from Table 4, mean diameter $\left(\mathrm{X}_{1}\right)$ was found to the major effect on the buckling in comparison to other variables as also found in the major researches, which may due to the high $\mathrm{F}$ value of 10242.64 for mean diameter, whereas the parameter frequency has been found less significant effects for buckling load. However, the interactions between the variables have no significant effect on buckling load. But on considering the main corrugation effect amplitude is found more effective as compared to frequency.

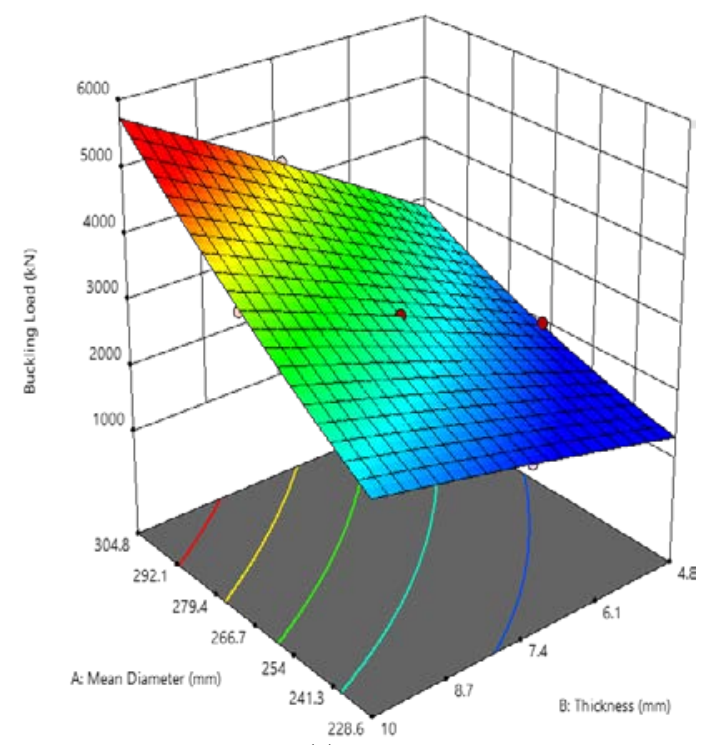

(a)

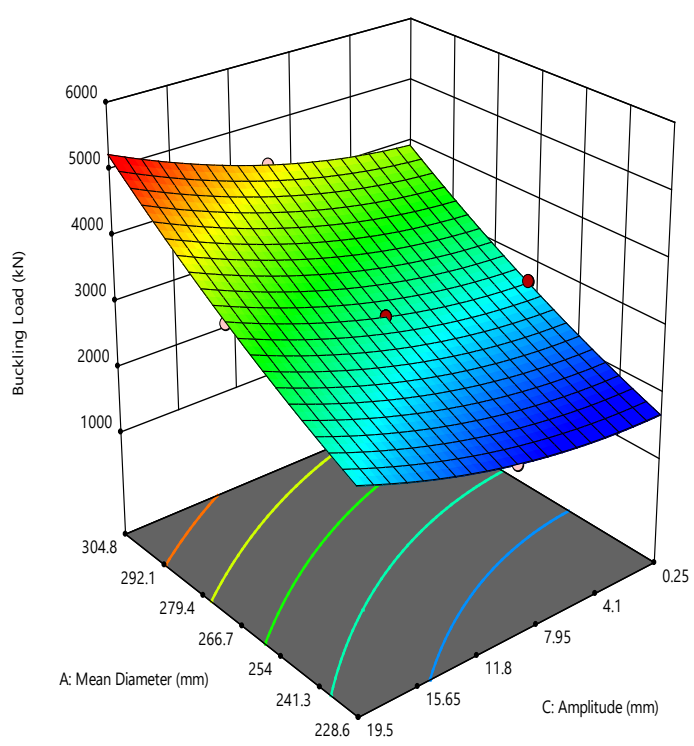

(b) 


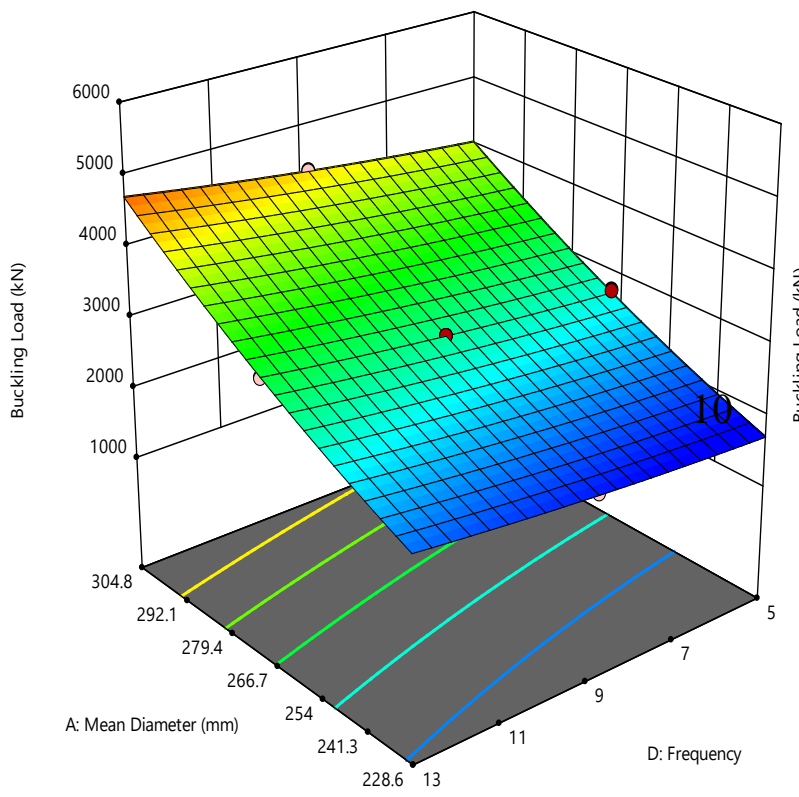

(c)

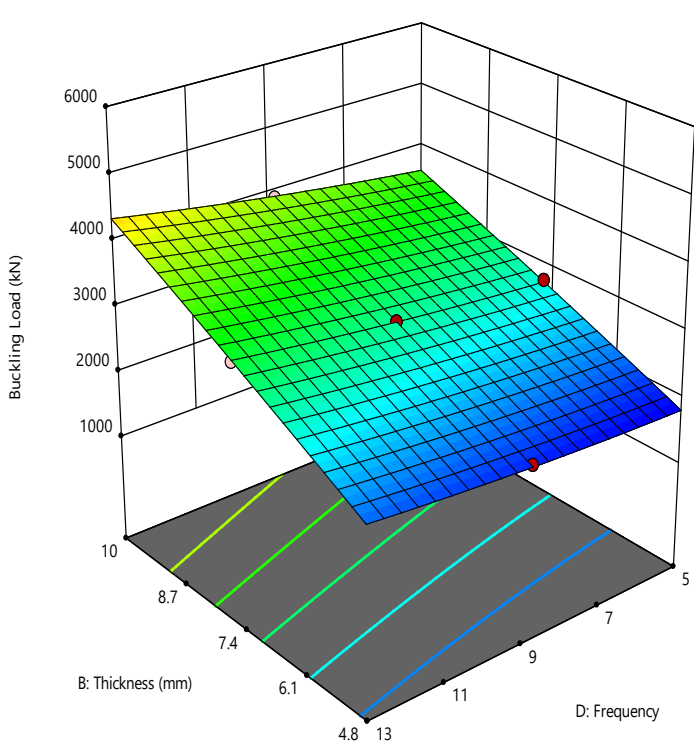

(e)

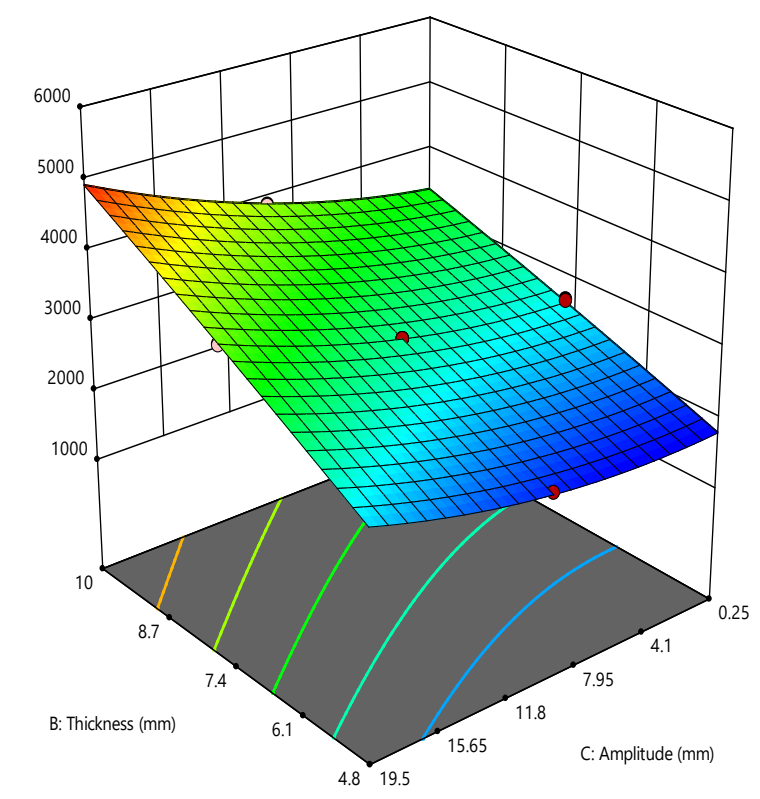

(d)

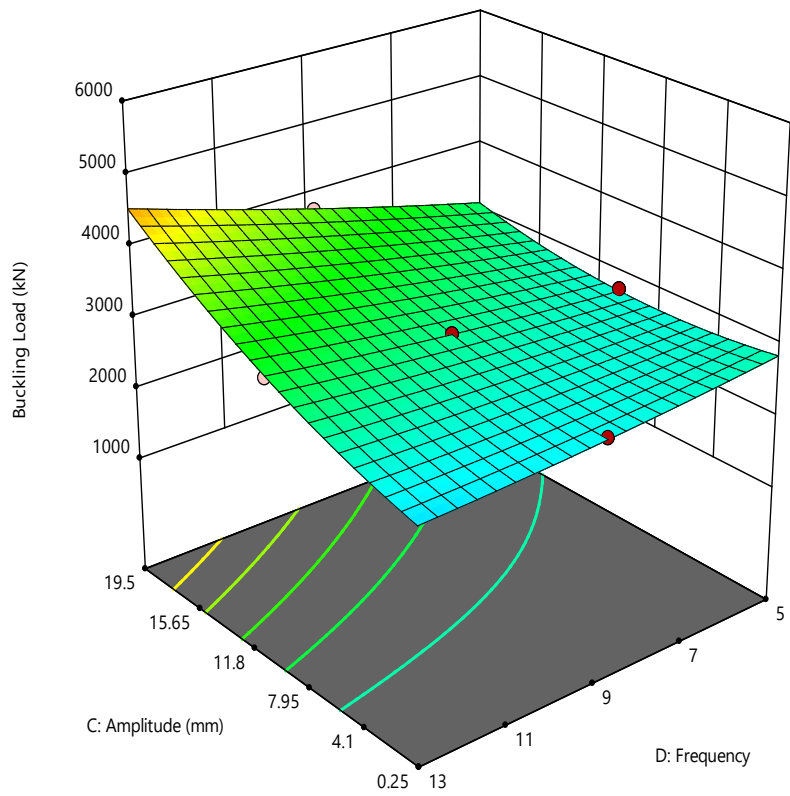

(f)

Fig 4: Response surface graph for the proposed sinusoidal corrugated tube for buckling load force; (a) effect of mean diameter and thickness (b) effect of mean diameter and amplitude, (c) effect of mean diameter and frequency, (d) effect of thickness and amplitude, (e) effect of thickness and frequency, (f) effect of amplitude and frequency. 


\section{Conclusion}

The main purpose of the investigation presented in this paper was to find out the buckling load of the corrugated geometry using Ansys Workbench is carried out. To get the standard number of experiments need to be perform to have all possible combinations results, design of experiment is applied with central composite design technique. Finally, to have a clear understanding about the effect of each geometric parameters over the buckling load response surface method is used. The regression analysis is calculated by using design expert for predicting the response behavior. The statistical significance, regression analysis and response surface analysis were carried out using the buckling results obtained values at variable operating conditions. A model was formulated to correlate the buckling load values with the variables to the responses. Based on models, the response surfaces behaviors are shown in Fig. 4 (a, b, c, d, e \& f) with two parameters effects over the buckling load and makes the influence effect much better to understand. Out of the corrugated parameters apart from mean diameter and thickness the amplitude have played an important role over the buckling load as compared to frequency. The kind of the structures are still under study and development as it is called as innovative structures.

\section{Acknowledgement}

The authors gratefully acknowledge Research and Development cell, Integral University, Lucknow for providing manuscript communication number IU/R\&D/2020-MCN000967 and kind support.

\section{References}

[1] Migita Y., Aoki T., Fukumoto Y. (1992), Local and interaction buckling of polygonal section steel columns, Journal of Structural Engineering 118, pp. 2659-76.

[2] Chen J, Jin W. L. (2010), Experimental investigation of thin-walled complex section concrete-filled steel stub columns, Thinwalled structures 48, pp. 718-24.

[3] Ventsel E, et al. (2002), Thin plates and shells: theory, analysis, and applications, Appl. Mech. Rev., 55, B72-3.

[4] Aoki T., Ji B. (2000), Experimental study on buckling strength of tri-tube steel members, In Coupled Instabilities in Metal Structures: CIMS'2000; pp. 283-290.

[5] Nassirnia M., et al. (2015), Innovative hollow corrugated columns: A fundamental study, Engineering structures 94, pp. 43-53.

[6] Deng X., et al. (2018), Experimental and theoretical study on crashworthiness of starshaped tubes under axial compression, ThinWalled Structures 130, pp. 321-31.
[7] Rahim M. R., et al. (2017), Comparative analysis of buckling load of circular and corrugated tubes by utilizing key performance indicators, International Journal of Applied Mechanics and Engineering 22, pp. 789-97.

[8] Azargohar R., Dalai A. K. (2005), Production of activated carbon from Luscar char: experimental and modeling studies, Microporous and mesoporous materials 85, pp. 219-25.

[9] Montgomery DC (2014), Design and analysis of experiments. 8th ed. New York: John Wiley and Sons.

[10] Gunaraj V., Murugan N. (1999), Application of response surface methodology for predicting weld bead quality in submerged arc welding of pipes, Journal of materials processing technology 88, pp. 266-75.

[11] Napier-Munn T. J., The central composite rotatable design JKMRC, The University of Queensland, Brisbane, Australia 2000; 10, pp. 1-9.

[12] Sen R. (1997), Response surface optimization of the critical media components for the production of surfactin, Journal of Chemical Technology \& Biotechnology: International Research in Process, Environmental AND Clean Technology 68, pp. 263-70.

[13] Box G. E., Hunter J. S. (1957), Multi-factor experimental designs for exploring response surfaces, The Annals of Mathematical Statistics 28, pp. 195-241.

[14] ANSYS ${ }$, Types of Buckling Analyses, in ANSYS ${ }^{\circledR}$ Release 17.1, Help System, Mechanical APDL, Structural Analysis Guide, Buckling Analysis: ANSYS, Inc.

[15] ANSYS ${ }$, Nonlinear Buckling Analysis, in ANSYS ${ }^{\circledR}$ Release 17.1, Help System, Mechanical Applications, Mechanical User's Guide, Analysis Types, Linear Dynamic Analysis Types: ANSYS, Inc.

[16] Yi S., et al. (2010), Application of response surface methodology and central composite rotatable design in optimizing the preparation conditions of vinyltriethoxysilane modified silica lite/polydimethylsiloxane hybrid pervaporation membranes, Separation and Purification Technology 71, pp. 252-6 